\title{
Design and Implementation of Analog Controller Based Single Phase Full Bridge Inverter for Photovoltaic Applications
}

\author{
Abhishek Ranjan*, Sunil Jalutharia, Harsh Garg, and Nitin Gupta \\ Department of Electrical Engineering, Malaviya National Institute of Technology Jaipur-302017, India
}

Received April 27, 2018; Accepted May 7, 2018; Published May 11, 2018

\begin{abstract}
This paper presents a low-cost design of the analog controller for the photovoltaic driven single-phase inverter to generate desired output voltage. The hardware set-up mainly consists of an inverter and an analog controller. The developed controller controls the output voltage of the inverter using SPWM (Sinusoidal Pulse Width Modulation) technique. The inverter, which is designed using Metal-Oxide-Semiconductor Field Effect Transistor (MOSFET) as a switch, generates high-quality output with reduced ripple content and less filtering requirement, making the whole setup cost-effective and efficient. A gate driver circuit is also employed to provide isolation between the inverter and the analog controller. The closed loop analog controller for the photovoltaic driven inverter is implemented and tested for various loads. In all these cases, the output voltage waveforms are of high quality with a lesser number of lower order harmonics. In this way, the paper presents a low-cost design of the inverter that can be used for low-power domestic applications.
\end{abstract}

Keywords: Analog Controller; H-Bridge Inverter; Sinusoidal Pulse Width Modulation (SPWM); MetalOxide-Semiconductor Field Effect Transistor (MOSFET); Gate Driver

\section{Introduction}

Many parts of the world are still in darkness with no sources of power. The researchers and scholars are working hard on non-conventional renewable sources of energy to provide an energy source in those regions. As these are environmentally friendly and clean energy sources, it has become an area of interest to the whole world. New and improved technologies are being introduced every day in this field. One of the most common sources of energy is solar energy, which is proven to be the most challenging one.

To extract solar energy, the photovoltaic (PV) array is used. It is based on the technology that converts solar energy to electrical energy. The use of PV array is not favored much because of the high cost of the installation. In spite of the high cost of installation, the use of PV array is increasing in most parts of the world to pump water, to get hot water in winters and even for lightening purposes [1]. So, the main focus is to make its implementation cost effective in houses, colleges, hospitals, rural areas, public places and even in small scale industries. An analog circuit for generating sine pulse width modulation (SPWM) along with a single phase full bridge inverter is capable of converting the DC output of the PV array to AC. SPWM is a very effective technique 
used widely in power electronics applications such as motor driver, UPS and the renewable energy system $[2,3]$. The controller helps maintain the power output as the radiation varies during the day. This $\mathrm{AC}$ output power can be used to run the various resistive and inductive loads. The analog controller has a proportional integrator (PI) controller that helps stabilize the output voltage at the motor. Even if the output voltage of the PV array fluctuates, the motor runs at a constant speed [4, 5]. A complete experimental setup has been built to demonstrate the utility of this project.

\section{Proposed Scheme}

The schematic diagram of the proposed scheme is shown in Figure 1.

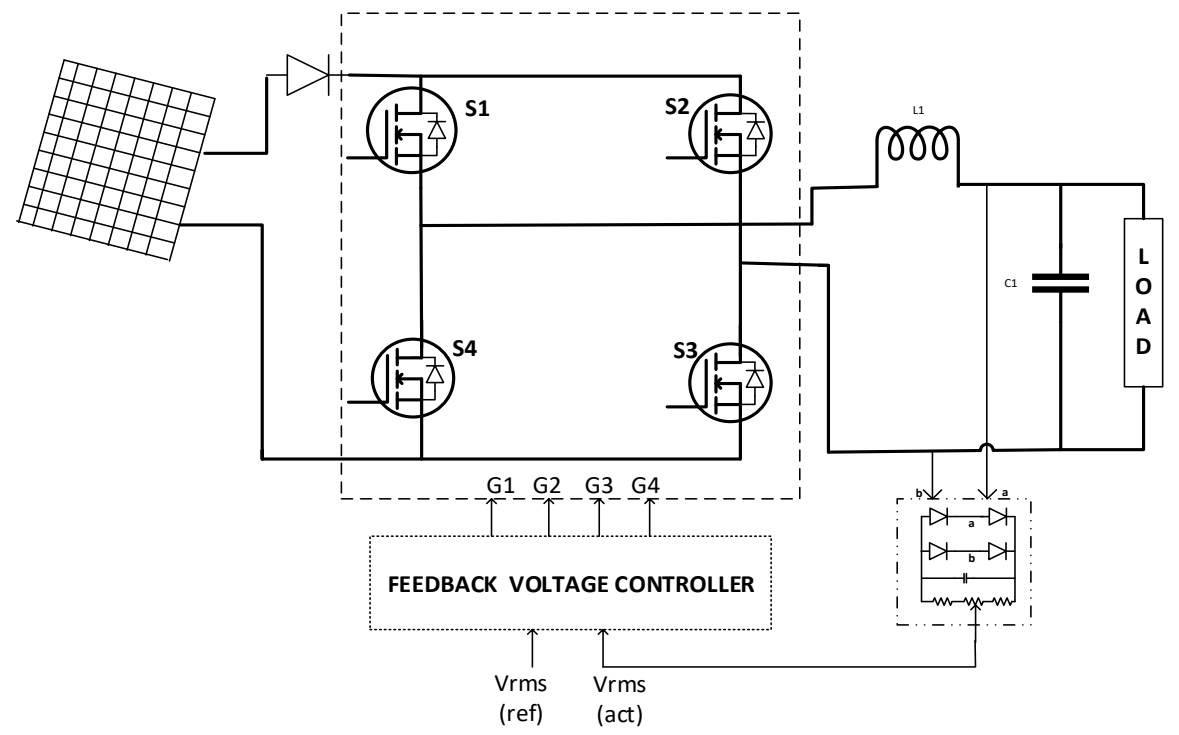

Figure 1. Schematic Diagram

The PV array is attached to a single phase full H-bridge inverter, which acts as a DC power source. An analog controller circuit is connected to the inverter, which provides the feedback to the system. This feedback helps in switching on and off of the power MOSFETs using SPWM technique. Hence, AC output is obtained from the inverter to drive an AC load. The output of the inverter depends on the solar radiation and its intensity. The components used in the circuit design are mentioned in Table 1. The major parts of the circuit are explained later.

\section{Single Phase H-bridge Inverter}

The inverter is a static power electronic circuit that converts the DC power to the $\mathrm{AC}$ power at desired output voltage and frequency. The most commonly used power transistors in inverters are MOSFETs and IGBTs. We used MOSFETs instead of IGBTs, because of the following reasons:

1) High switching frequency

2) Less switching power loss 
3) Lesser cost with comparable efficiency

The single phase full bridge inverter is constructed by using two half-bridge inverters [6, 7]. The inverter circuit consists of four MOSFET (Metal oxide semiconductor field effect transistor) switches, four diodes, DC source and load. Each MOSFET is connected with an anti-parallel diode to support the reverse conduction. In the full H-bridge inverter circuit, the four switches S1, S2, S3 and S4 are connected as shown in the Figure 2. The gate pulses are shown in Figure 3 for S1 \& S3 and S2 \& S4, respectively.

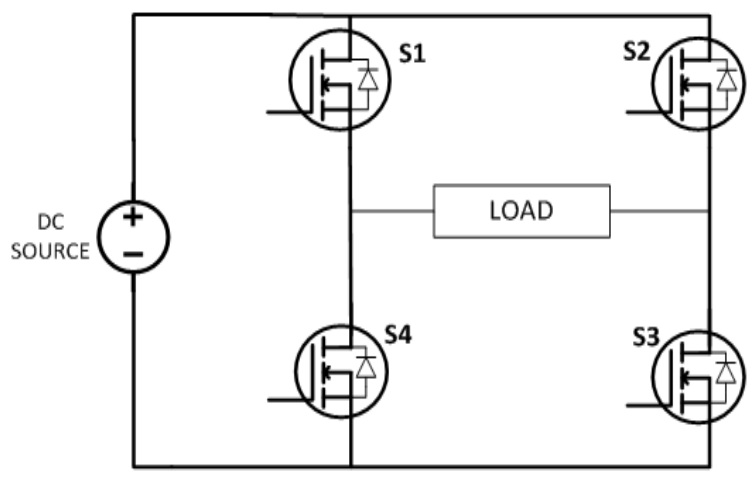

Figure 2. Single phase full $\mathrm{H}$-bridge inverter
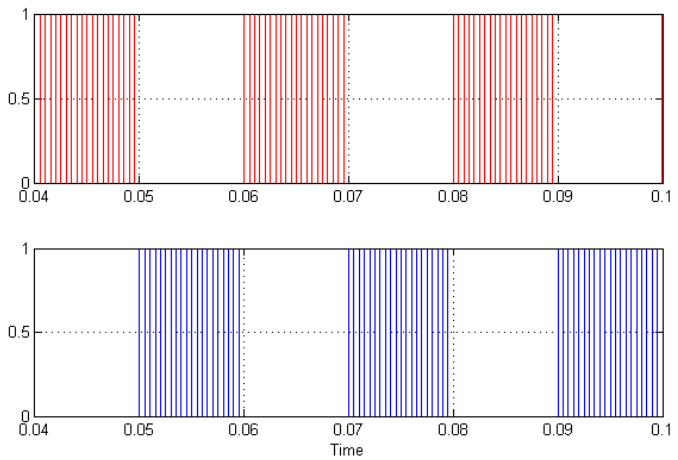

Figure 3. Gate Pulses (MATLAB)

The gate triggering pulses $G_{1}, G_{2}, G_{3}$ and $G_{4}$ are generated by using SPWM technique. The gate pulses $\mathrm{G}_{1}, \mathrm{G}_{2}, \mathrm{G}_{3}$ and $\mathrm{G}_{4}$ are used to control the MOSFET switches $\mathrm{S} 1, \mathrm{~S} 2, \mathrm{~S} 3$ and S4, respectively [8].

During the positive half cycle, the switches S1 \& S3 will conduct, which are triggered simultaneously by gate triggering pulses $G_{1}$ and $G_{3}$, respectively. During the remaining half cycle, the switches S2 \& S4 will conduct and are triggered simultaneously by gate triggering pulses $\mathrm{G}_{2}$ and $\mathrm{G}_{4}$, respectively. 


\section{Sinusoidal Pulse Width Modulation Technique}

The sinusoidal pulse width modulation (SPWM) is an extension of multiple pulse modulation technique. In SPWM, several pulses per half cycle are used and the pulsewidth is a sinusoidal function of the angular position of the pulse in a cycle as shown in Figure 4.

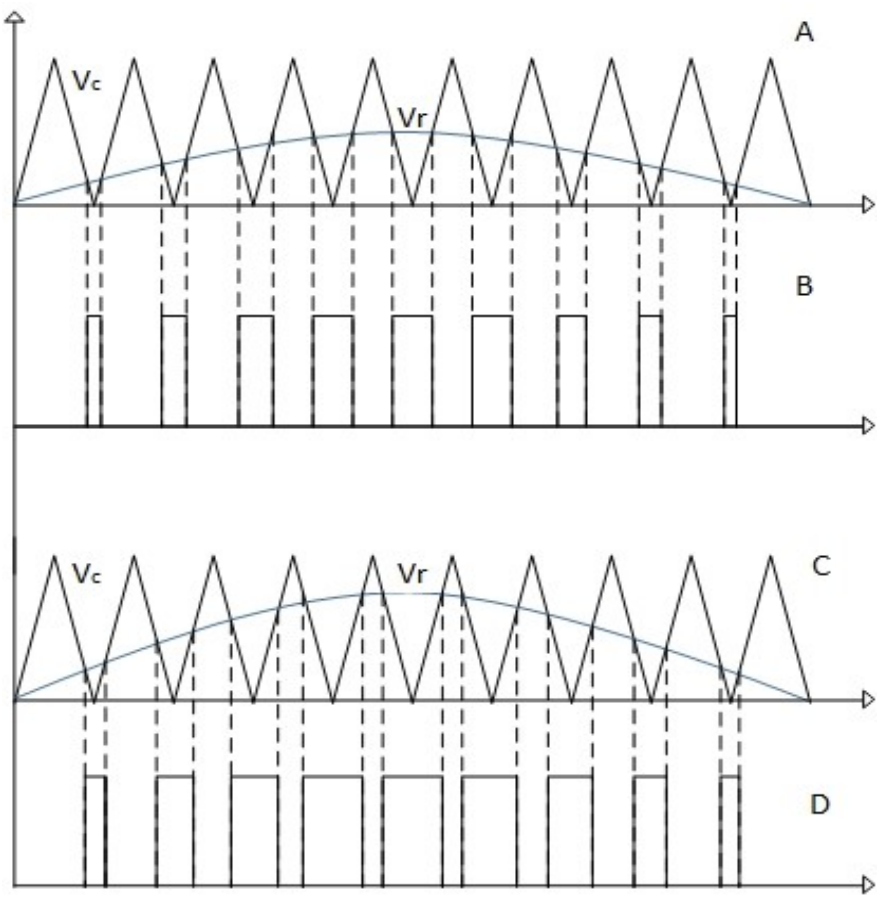

Figure 4. Generation of SPWM waveform

In this method, the high-frequency carrier signal (i.e., the unipolar triangular wave) is compared with a reference or modulating signal (i.e., the sinusoidal wave) to generate firing pulses. The firing pulses are generated, when the amplitude of the sine wave exceeds the amplitude of the repetitive signal. The generation of SPWM waveform for two different modulation index $\mathrm{M}_{1} \& \mathrm{M}_{2}$ is shown in part $\mathrm{A}, \mathrm{B}, \mathrm{C}$ and $\mathrm{D}$ of Figure 4 and it is also depicted below:

A) Comparison of carrier wave $V_{c}$ with modulation index $M_{1}$

B) Firing pulses for modulation index $M_{1}$

C) Comparison of carrier wave $\mathrm{V}_{\mathrm{c}}$ with modulation index $\mathrm{M}_{2}\left\{\mathrm{M}_{2}>\mathrm{M}_{1}\right\}$

D) Firing pulses for modulation index $\mathrm{M}_{2}\left\{\mathrm{M}_{2}>\mathrm{M}_{1}\right\}$

The output voltage and the output frequency of the inverter are regulated by SPWM technique. The output voltage can be varied by varying the amplitude of the modulating signal i.e., the sine wave. The output frequency is decided by the frequency of the modulating signal i.e., the sine wave. The quality of the output voltage waveform can be improved by increasing the number of pulses over each half cycle, which reduces the ripples and decreases the filtering requirement. This is made possible by varying the frequency of the carrier signal i.e., the triangular wave. 
Moreover, if we increase the frequency of the repetitive carrier signal, the frequency of the predominant harmonics increases, and their filtering becomes easier. Thus, the size of the required filter is reduced. Hence, the SPWM technique helps in reducing harmonic content and the cost of the set-up is significantly reduced due to the reduced size of the filter as mentioned in this document.

\section{Analog Controller}

The analog controller as shown in Figures 5 and 6 is an IC based analog circuit, which is used to produce desired AC supply from fluctuating DC supply i.e., the PV array. It is used to vary the pulse width required to obtain a fixed AC supply for the smooth operation of AC loads.

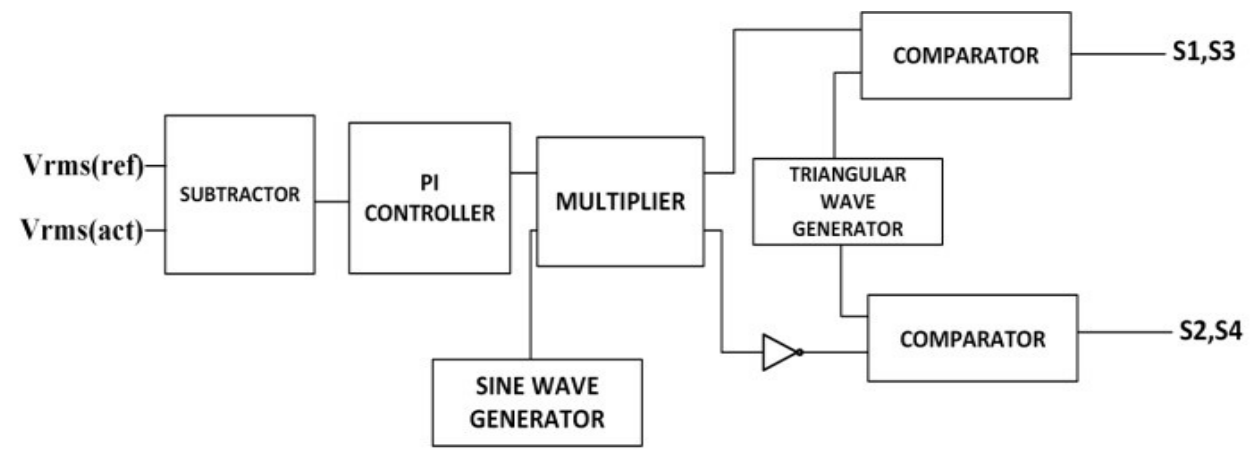

Figure 5. Block Diagram of an Analog Controller

The deviation of the actual root-mean-square (RMS) value from the set RMS value is fed to the PI controller. The amplitude of the sine wave is made proportional to the error signal by multiplying the output of the PI controller with the reference sine wave of the SPWM controller. The variable amplitude sine wave obtained from the multiplier AD633 is compared with the unipolar triangular wave to generate pulses for the gate triggering circuit of the inverter.

The analog controller is segmented into four stages as follows:

1) Difference amplifier

2) Proportional Integrator controller

3) Multiplier

4) Comparator

The reference RMS voltage (i.e., the required constant output $\mathrm{AC}$ voltage) and the actual feedback RMS voltage are given as the inputs of the difference amplifiers.

The error signal generated from the first stage is fed to the Proportional-Integral Controller stage (Second stage). The PI controller continuously tries to minimize the error between the reference RMS voltage and the actual feedback RMS voltage. The output of the PI controller and the sine wave generated from the sine wave generator are fed to the inputs of a multiplier AD633 (Third stage). The output of the multiplier can be realized by the following equation 


$$
A_{M}=\frac{\left(A_{P I}\right) \times\left(A_{S I N E}\right)}{10}
$$

where $A_{M}, A_{P I}$ and $A_{S I N E}$ are the amplitude of the multiplier, PI controller, and sine wave, respectively.

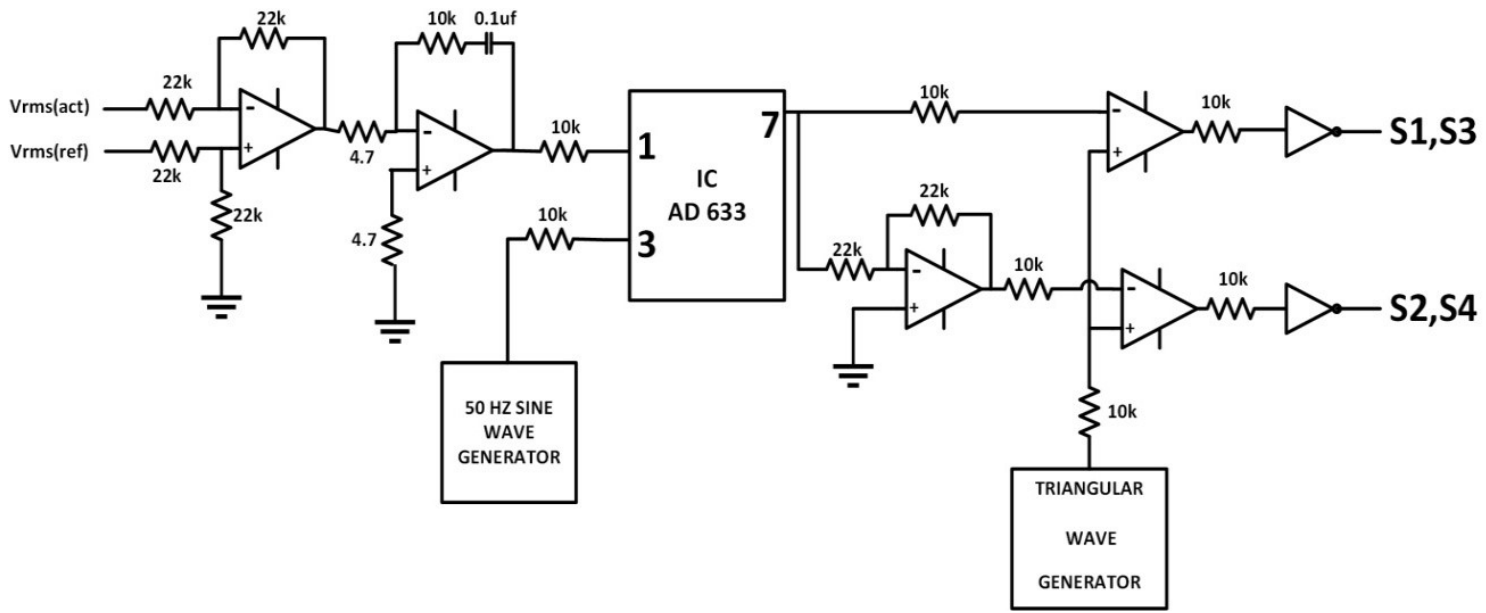

Figure 6. Circuit Diagram of Analog Controller

The output of the third stage is given to the inputs of the comparator (Fourth Stage). During the positive half cycle, the variable amplitude sine-wave is compared with the unipolar triangular wave generated from the triangular wave generator to generate the gate pulse. During the negative half cycle, the negative portion of the variable amplitude sine-wave is first inverted by inverting amplifier, and then compared with the unipolar triangular wave. Hence, the gate triggering pulses are generated for both positive and negative half cycles shown in Figure 16. The hardware implementation of the analog controller designed on the printed circuit board (PCB) is shown in Figure 7.

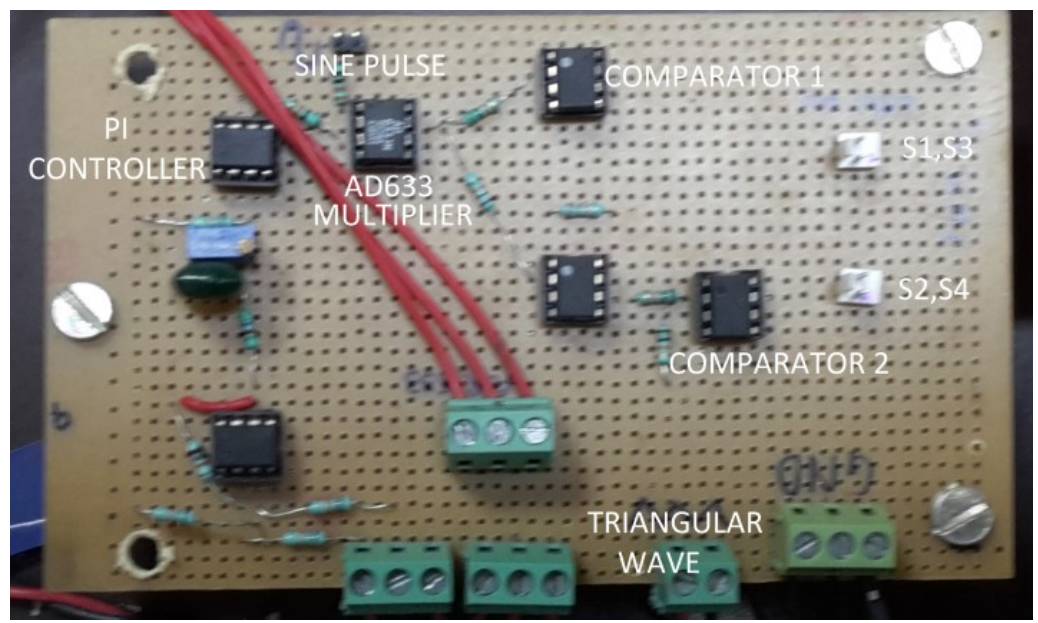

Figure 7. Hardware Design of Analog Controller 


\section{Gate Driver}

Agate driver is an amplifier circuit employed to trigger the high-power transistor like IGBTs and MOSFETs from a low power output of the feedback voltage controller. The gate driver circuit is shown in Figure 8.

Isolation is required between the high-power circuit and the low-power control circuit in order to avoid the high-power circuit current to flow into the control circuit under faulty conditions. The isolation is provided by TLP250, which is an optocoupler device transferring electrical signals between two isolated circuits [9]. It is suitable for gate driving circuits for IGBT and power MOSFET. The input side has a LED and the receiving side has a photodetector. The propagation delay of the driver is relatively low, which typically lies between $0.15 \mu$ s to $0.5 \mu$ s as the input and output are optically isolated. The maximum operating frequency is around $25 \mathrm{kHz}$.

TLP250 receives $3 \mathrm{~V}$ SPWM pulse generated by the analog controller. Then, TLP250 amplifies the $3 \mathrm{~V}$ gate-pulse to more than $10 \mathrm{~V}$ gate-pulse required to trigger MOSFET IRF540N as specified in its datasheet. Hence, TLP250 performs two main functions that are amplification of gate pulse and isolation of high power circuit from the controller circuit. The hardware implementation of the gate driver circuit is shown in Figure 9.

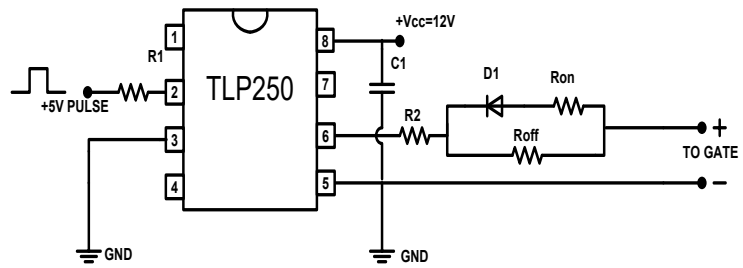

Figure 8. Schematic Circuit Diagram of TLP250 Gate Driver Circuit

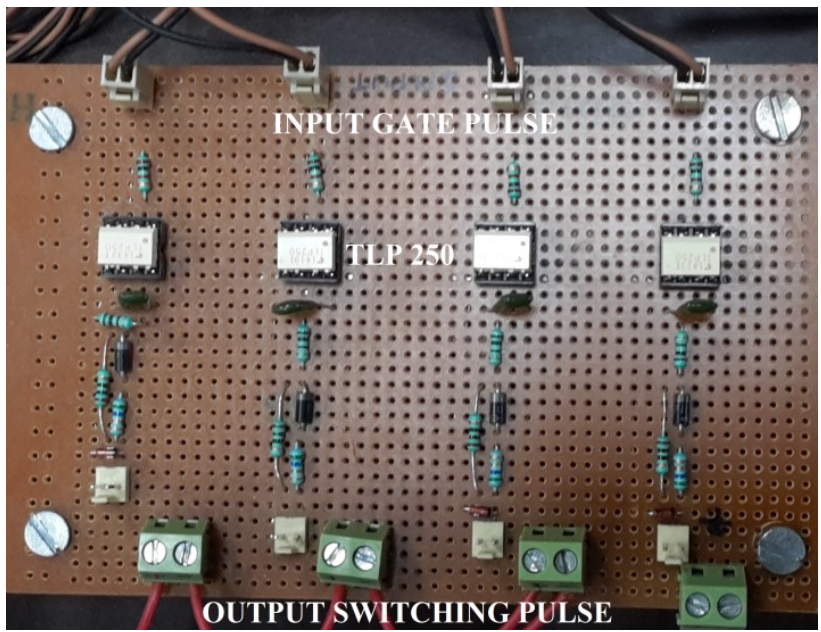

Figure 9. Hardware Design of Gate Driver Circuit 


\section{Sine Wave Generator}

The Sine-Wave generator as shown in Figure 10 is used to generate a sinusoidal signal that is used as a reference signal for the generation of gate pulses using SPWM technique. This Sine-Wave generator utilizes the concept of the Wein's Bridge oscillator using op-amps. The Sine-Wave generator circuit generates repetitive waveforms of fixed frequency and amplitude without any external input signal.

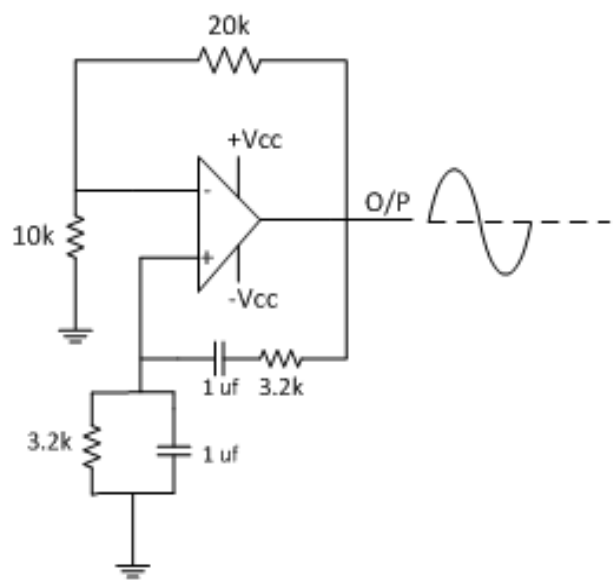

Figure 10. Schematic Circuit Diagram of Sine Wave Generator

The frequency is decided by the equation:

$f=\frac{1}{2 \pi R C}$

The hardware implementation of the Sine-Wave generator is shown in Figure 11.

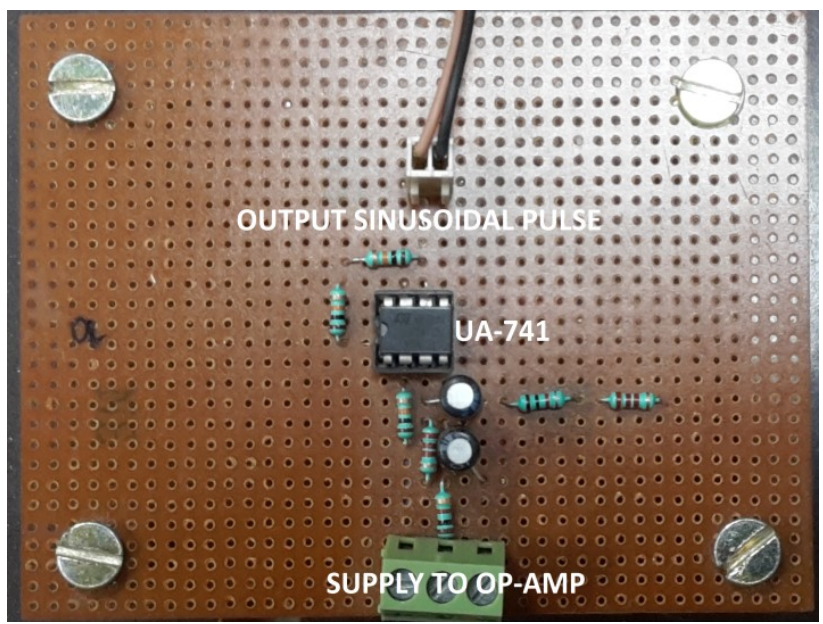

Figure 11. Hardware Design of Sine-Wave Generator 


\section{Experimental Results and Set-up}

The laboratory prototype was constructed using a PV array, single phase MOSFET based inverter and a feedback analog controller. The overall hardware circuitry prepared for pulse generation is shown in Figure 12.

The D.C. output of the PV array is coupled to the input of single phase inverter in order to obtain AC output voltage (according to requirement) and frequency $50 \mathrm{~Hz}$. The output voltage of the inverter is controlled by generating suitable firing sequence for the inverter using an analog controller, which is present in feedback to the main power circuit.

In the analog controller, the output of the inverter is compared with the reference voltage to generate a suitable error signal. The error signal is passed to the PI controller and the output of the controller is then multiplied with the sine wave using a multiplier IC AD633. This is done to make the amplitude of sine wave proportional to the generated error signal.

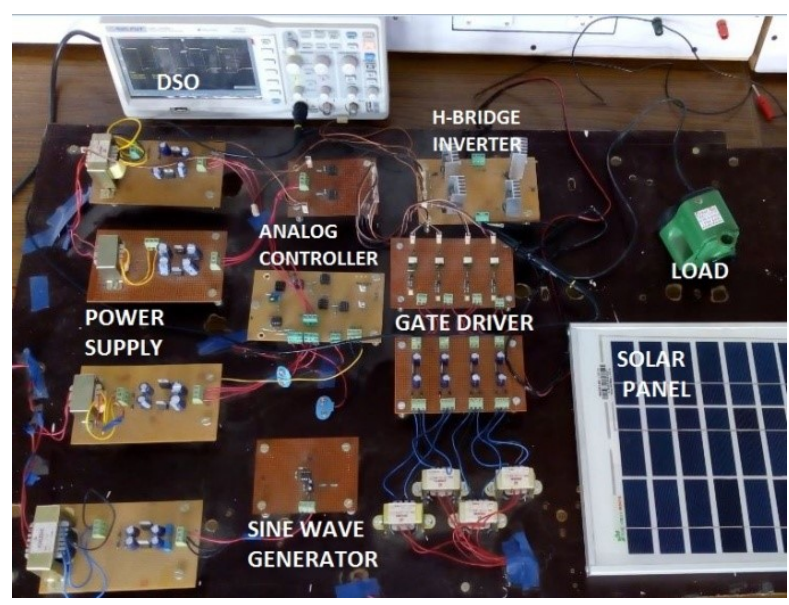

Figure 12. Complete Experimental Set-Up

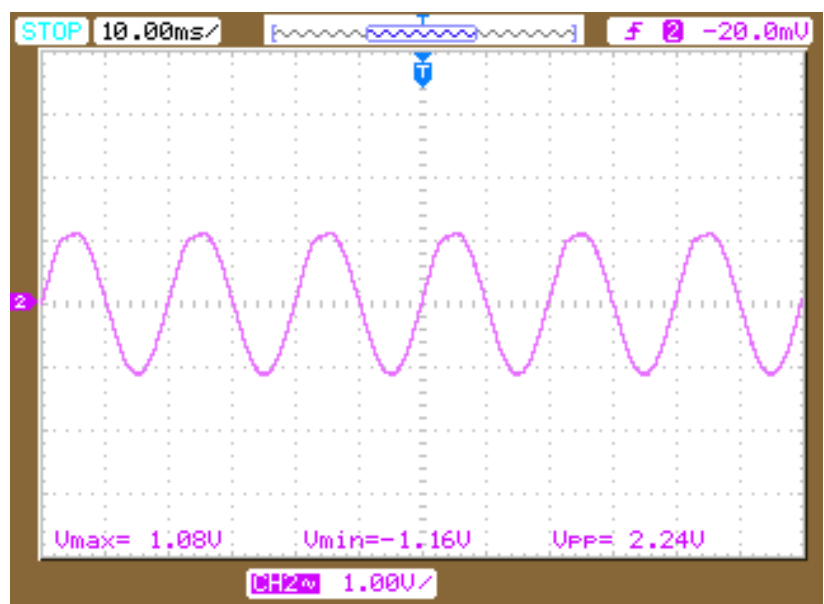

Figure 13. Sinusoidal Waveform 


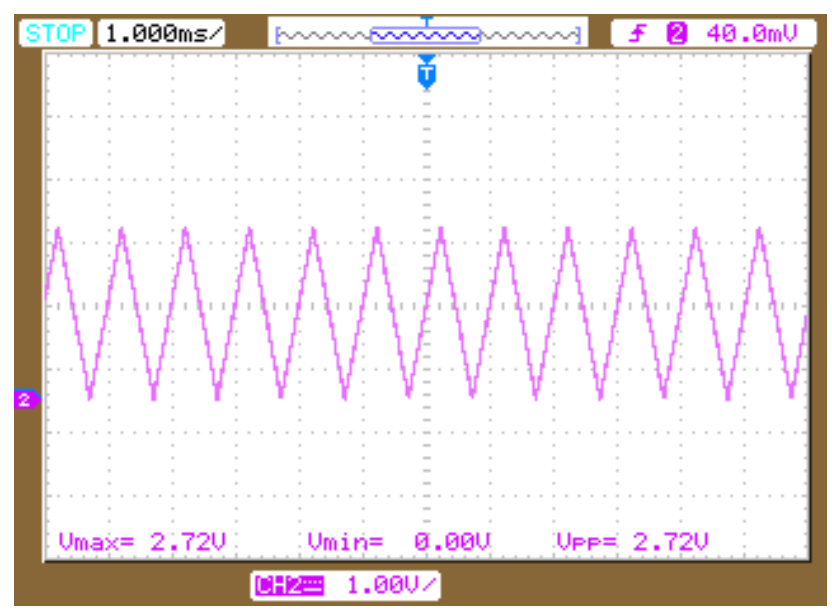

Figure 14. Unipolar Triangular Waveform

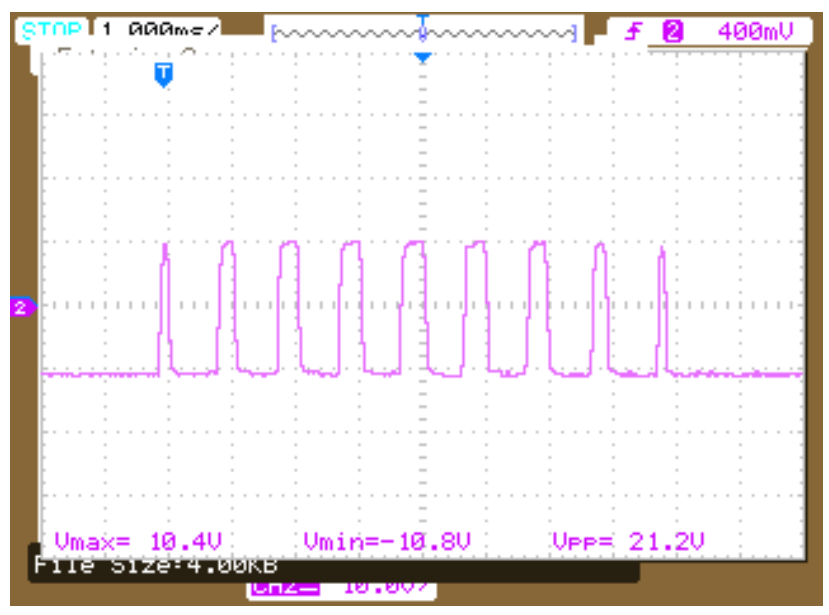

Figure 15. Generated SPWM Waveform

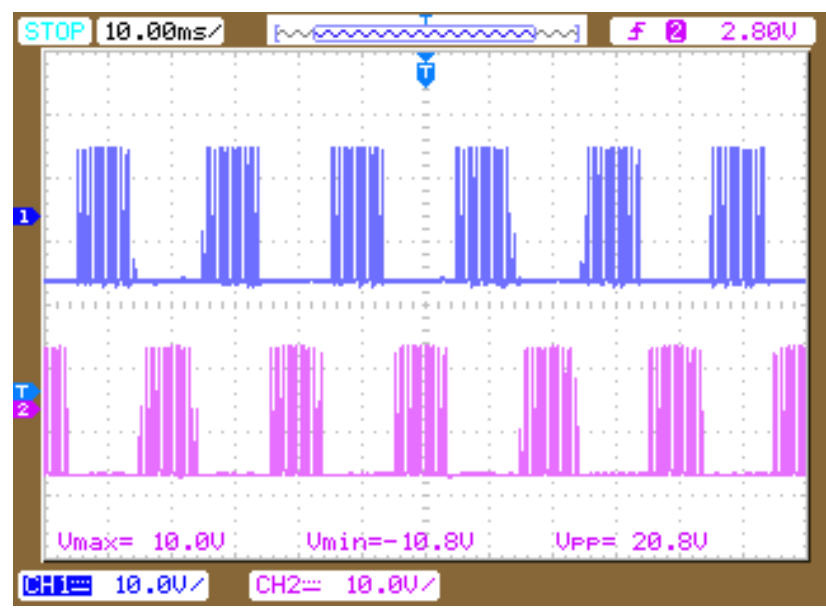

Figure 16. Triggering Gate Pulse 


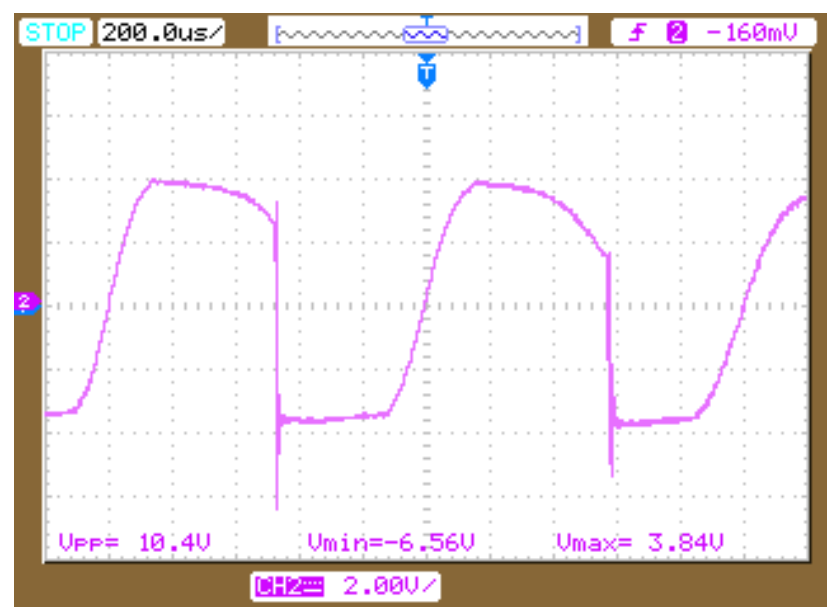

Figure 17. Output Voltage Waveform

Figure 13 shows the sinusoidal waveform generated by the Sine-Wave generator and Figure 14 shows the waveform of the triangular wave generator. The output of the multiplier is compared with a unipolar triangular wave to generate suitable firing gate pulse during both the positive and negative half cycle of the sinusoidal waveform.

The outputs of analog controller as shown in Figures $15 \& 16$, i.e., $\mathrm{G}_{1}, \mathrm{G}_{2}, \mathrm{G}_{3}$ \& $\mathrm{G}_{4}$ are given to the TLP250 driver circuit. The driver circuit forms a bridge between the analog controller and the inverter circuit. It provides the firing pulses to the gate terminal of the individual MOSFET switch. The output of the inverter is shown in the Figure 17.

The desired output voltage is obtained by giving suitable firing sequence generated by SPWM based analog controller. The output voltage and frequency have been mentioned in Table 2.

Table 1. Components Used in the Circuit

\begin{tabular}{|l|l|l|}
\hline S.No. & Component Name & Rating \\
\hline 1. & PV Array & $24 \mathrm{~V}, 20 \mathrm{~W}$ \\
\hline 2. & MOSFET(IRF540N) & VDS $=100 \mathrm{~V}, 23-33 \mathrm{~A}$ \\
\hline 3. & Op-Amp(UA-741) & $\pm 18 \mathrm{~V}, 1.7-2.8 \mathrm{~mA}$ \\
\hline 4. & AD633 & $\pm 15 \mathrm{~V}, 4-6 \mathrm{~mA}$ \\
\hline
\end{tabular}

Table 2. Output Data

\begin{tabular}{|l|l|l|}
\hline S.No. & Parameter & Output values \\
\hline 1. & Voltage & $0-24 \mathrm{~V}$ \\
\hline 2. & Frequency & $50 \mathrm{~Hz}$ \\
\hline
\end{tabular}

\section{CONCLUSIONS}

In this paper, an efficient and cost-effective control strategy for the single phase full bridge inverter using an analog controller has been presented. The analog controller consisting of low-cost analog components is used to control the output voltage using SPWM technique. SPWM technique helps in reducing filtering requirement by eliminating predominant harmonics along with the output voltage control. Thus, the size 
as well as the cost of the overall setup is reduced. This paper eliminates the requirement of a microcontroller. The overall system is first simulated using MATLAB, and then the hardware circuit is designed. The experimental results on the laboratory prototype are presented to validate the control strategy. The SPWM based single phase inverter is tested for various loads, where it is observed that the output current waveform is smooth due to less harmonic content and less total harmonic distortion (THD). THD can be reduced further by increasing the frequency of the carrier wave, and resulting in much smoother output waveforms. Thus, the paper presents the low-cost design and implementation of the analog components based control technique of a single phase inverter, which can be used to simplify many real life problems.

\section{CONFLICTS OF INTEREST}

We declare that there is no conflict of interests regarding the publication of this paper.

\section{REFERENCES}

[1] J. Xu, K. Han, "The Single-Phase Inverter Design for Photovoltaic System" in Proceedings of International Symposium on Computer, Consumer and Control (IS3C), Xi'an, July 2016. DOI: 10.1109/IS3C.2016.95

[2] P.S. Bimbhra, "Power Electronics", Khanna Publishers, 2012. pp. 309.

[3] L. Umanand, "Power Electronics: Essentials \& Applications", Wiley, 2009. pp. 80.

[4] Y.C. Kuo, L.J. Liu, H.C. Lee, “Analog controller IC design for single-stage photovoltaic inverters" in Proceedings of International Conference on Fuzzy System Knowledge Discovery, China, July 2011. DOI: 10.1109/FSKD.2011.6020035

[5] J. Luecke, "Analog and Digital Circuits for Electronic Control system applications", Elsevier, 2005. pp.43.

[6] S.K. Mandal, "Power electronics", Edition India: Mc Graw Hill Education, 2014. pp. 81.

[7] M.H. Rashid, "Power Electronics: Circuits, Devices, and Applications" Third Edition, Prentice Hall, 2011.pp. 226.

[8] N. Sasidharan, J.G. Singh, "A Novel Single Stage Single Phase Reconfigurable Inverter Topology for a Solar Powered Hybrid AC/DC Home", IEEE Transaction on Industrial Electronics, vol. 64, pp. 2820-2828, 2016.

[9] J.N. Khan, "Design considerations in using the inverter gate driver optocouplers for variable speed motor drives", White Paper, Avago Technologies, 2010.

Article copyright: (C) 2018 Abhishek Ranjan, Sunil Jalutharia, Harsh Garg and Nitin Gupta. This is an open access article distributed under the terms of the Creative Commons Attribution 4.0 International License, which permits unrestricted use and distribution provided the original author and source are credited.

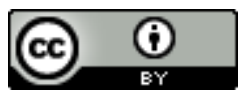

